\title{
Organizational Image Repair Tactics and Crisis Type: Implications for Crisis Response Strategy Effectiveness
}

\author{
John Gribas (1), a,b James DiSanza (1), a Nancy Legge (1), \\ and Karen L. Hartman (1) ${ }^{a}$
}

aDepartment of Communication, Media, and Persuasion, Idaho State University, Pocatello, Idaho, USA; bAlso at College of Arts and Letters, Idaho State University, Pocatello, Idaho, USA

\begin{abstract}
Existing models of organizational crisis response effectiveness provide useful insights but are limited in terms of offering a guide for practitioners dealing with actual crisis situations. This analysis examines the relative effectiveness of image repair tactics based on differences in root causes of crisis events. Results suggest that certain image repair tactics are seen as the most and the least effective regardless of crisis type. At the same time, there were some differences across crisis types that could guide practitioner tactic choices. Limited results here and in past research raise questions about whether image repair tactic effectiveness can be usefully mapped to situational variables, such as audience or crisis type. This article concludes with discussion on this matter and suggestions for future research.
\end{abstract}

KEYWORDS: Organizational crisis; image repair; crisis type; root cause; strategy effectiveness

Organizations must be continually prepared to respond to crises, recognizing the potential for high financial and/or reputational costs. Crisis practitioners must understand how to deal with crisis situations quickly, avoid speculation, and apply strategy grounded in "insights that can be applied effectively and ethically under extraordinary pressures of limited time and severe scrutiny of the organization's legitimacy" (Heath, 2010, p. 3). Ideally, clear crisis plans based on such strategy are readily available, but the reality is often quite different. According to a 2014 international crisis management survey, $20 \%-25 \%$ of

CONTACT John Gribas, PhD • E-mail: gribjohn@isu.edu • Department of Communication, Media, and Persuasion, Idaho State University, 921 South 8th Ave., Stop 8115, Pocatello, ID 83209-8115, USA 
respondents, including organizations that classified themselves as highrisk operations, did not have a plan ("Preparing for Crisis," 2014).

Understanding how and what to communicate during a crisis is a critical part of any crisis plan. It is essential that researchers engage in work to help determine what constitutes effective crisis communication and what industry best practices should be. However, according to Coombs (2014), "effective applied communication does help to improve the field to which it is applied. Unfortunately, the academic literature on crisis communication is both vast and difficult to assess at times, making it of limited value to crisis communicators" (para. 30).

Some have called for more empirical testing of crisis communication tactics (An \& Cheng, 2010; Avery, Lariscy, Kim, \& Hocke, 2010; Blaney, 2016; Pfeffer \& Sutton, 2006), and in response to that call, this quantitative analysis examines the relative effectiveness of image repair tactics for various organizational crisis types. It applies Benoit's typology, one of the most recognized frameworks for examining corporate, political, and organizational crisis responses (see Benoit, 1995b, 2006; Benoit \& Brinson, 1994; Benoit \& Czerwinski, 1997; Brinson \& Benoit, 1999; Coombs \& Schmidt, 2000; DiSanza, Legge, Allen, \& Wilde, 2012; King, 2006). Most research using the typology comprises qualitative case studies focused on singular crisis events. These approaches have obvious limitations in terms of making general claims about the impact of different tactics in crisis situations. Because testing the effectiveness of such claims is vital if research is to advise practitioner choices, research must begin to map tactical choices onto contingencies like audience and crisis type. This study, therefore, was guided by the following research question: What specific image repair tactics result in more positive and/or more negative perceptions of an organization based on differences in crisis type?

\section{Literature Review}

Some quantitative tests of image repair in organizations have focused on the relative effectiveness of different tactics. For example, Twork and Blaney (2013) tested the premise that mortification combined with promises of corrective action would be more effective than mortifica- 
tion only. They found no significant differences between approaches. Dawar and Pillutla (2000) discovered that, in the case of a harmful consumer product, clear mortification, clear recall measures (corrective action), and restitution (compensation) were superior to stonewalling and ambiguous attempts at mortification and corrective action. In a related study, Spence, Lachlan, and Omilion-Hodges (2016) looked for differences in the impact of mortification and corrective action on participants' perceptions of organizational reputation; however, both were found to be equally effective. Cos, Worrell, and Blosenhauser (2016) exposed audiences to different paired tactics and found that audiences exposed to mortification and corrective action had more positive feelings toward the organization than those exposed to minimization and transcendence. When respondents in the study were asked what they would have liked to have heard from the offending organization, $53 \%$ responded with comments that could be categorized as corrective action.

Some past work has tied image repair tactic effectiveness to crisis type in ways that are similar to our goals in this study. Most of this work tests Coombs's (2007) situational crisis communication theory (SCCT). SCCT suggests that crisis managers will select more effective persuasive response tactics if they understand the kind of crisis situation they are experiencing. Based on attribution theory, Coombs's (2006) theory suggests that the reputational threat a crisis presents is defined by the audience's perception of four things: (a) crisis type, as determined by the audience's perception of whether responsibility for the crisis was external or internal; (b) severity of the damage; (c) whether organizational history includes many or few past crises; and (d) relationship history, defined as the audience's attribution of the quality of the relationship it has with stakeholders.

Audience attributions are seen as resulting from how the media "frame" and cover the crisis-specifically the facts and values that they choose to emphasize - thereby influencing how the audience perceives the crisis. According to Coombs (2007), except in cases of crises that unfold online, "the frames used in the news media reports are the frames that most stakeholders will experience and adopt" (p. 171).

Coombs's (2007) model includes a set of recommended response 
tactics to match crisis type that should produce maximum image repair benefits. Empirical support for matching response tactics to crisis types is mixed. Coombs and Holladay (1996) found that matching crisis response to crisis type produced significantly more reputational benefits to the organization than mismatched responses, although the effect sizes were small. Other studies (Brown \& White, 2011; Claeys, Cauberghe, \& Vyncke, 2010) found no significant improvement in organizational reputation when crisis strategies were matched to crisis type.

This study is consistent with the goals of work grounded in Coombs's model. However, as explained later, we take a different approach to operationalizing crisis type in an attempt to uncover findings that are both more robust and more useful for real-world practitioner applications.

\section{Method}

This study adds to the body of quantitative research testing image repair strategy effectiveness. It was designed as a continuation of earlier exploratory work (Gribas, DiSanza, Legge, Hartman, \& Santee, 2016) in which audience type, based on audience perceptions of responsibility and severity, was considered as a possible influence on tactic impact. In the current study, the focus is not on audience type but rather on crisis type.

\section{Classifying Organizational Crisis Types}

The approach to defining crisis type here is grounded in practical application. When crises arise, public relations $(\mathrm{PR})$ practitioners are called on to make quick messaging decisions that are truthful and ethical, that protect affected publics, and that also minimize image damage and/ or maximize image repair. As noted earlier, it would be best for these decisions to be based on solid, empirically verified guidelines rather than on speculation or instinct.

Models provided by both Benoit (1995a, 2015) and Coombs (2006) offer valuable insight into the world of organizational image repair; however, both are limited in their capacity as the basis for a real-world, real-time guide. Benoit's (1995a, 2015) model is, by design, a typology 
only rather than a predictive tool. The many case studies based on the typology offer valuable help, as practitioners, aware of these case studies, can draw connections between a current crisis and what has worked (and not worked) in the past in a similar situation. However, PR practitioners would need to be extremely well read to be aware of enough cases to make this approach viable. Also, inevitable differences between past organizational crises and any current situation make even the most informed reasoning by analogy tenuous at best.

Coombs's (2006) SCCT model, on the other hand, is designed for predictive insight. As noted, empirical support for its theorized predictions is limited. Yet even if SCCT had stronger empirical support, its usefulness to PR practitioners would be questionable. To apply Coombs's model, a PR manager would need to accurately gauge the following in the very early stages of a crisis: audience determination of responsibility as external or internal, audience assessment of damage severity, audience awareness of the organization's past crisis history, and audience's judgment of the relationship quality between organization and stakeholders. Gauging such perceptual complexity would be difficult, if not impossible. These are essentially individual-level variables, and as Benoit (2015) has pointed out, audiences are not monolithic. For example, some may view crisis damage as relatively small, while others see the same result as severe, or while some are keenly aware of past crises in the organization's history, others are unaware of that history. It is likely, especially in the early stages of a crisis, that the organization is "simultaneously in multiple situations" (Benoit, 2015, p. 38). Additionally, almost every organizational crisis today unfolds online as well as in the mainstream media. The explosion in online news sources, social media, and microblogs has reduced the mainstream media's ability to frame the particulars of a crisis in any unified way, likely exacerbating the perceptual fragmentation in any target audience.

To provide usable advice for practitioners, we wanted something more than an image repair strategy typology, but we also wanted a way to assess crisis type based on something less complex and more immediately accessible than individual attributional and perceptual variations. We considered Campbell's (1999) list of nearly 40 crisis types, Coombs's (1999) somewhat reduced list (natural disasters, malevolence, technical 
breakdowns, human breakdowns, challenges, megadamage, organizational misdeeds, workplace violence, and rumors), and numerous PR or business communication textbooks that contain similarly extensive lists of possible threats to organizations. From this, we sought to identify a small number of mutually exclusive and reasonably exhaustive categories. The result was a four-category scheme for organizational crisis type based on general root cause: malevolence, managerial failure, systemic failure, and natural disaster.

A malevolence crisis occurs when an actor inside or outside the organization takes serious action, often to express anger toward the organization. Such action includes shootings, bombings, sabotage, product tampering, or malicious rumors designed to damage the organization. For example, in 1982, a still unknown person laced Tylenol capsules with potassium cyanide, killing seven people. Other examples include the Pepsi syringe scare of 1993 and the Wendy's finger incident in 2005. In these cases, people made fraudulent claims about a product to bring a tort lawsuit against the firm.

In a managerial failure crisis, management knowingly acts in ways that cause harm or risk of harm for organizational stakeholders or knowingly chooses not to act to prevent such harm or risk. Lerbinger (1997) suggested that manager-created crises usually result from some combination of skewed management values, deception, and misconduct. The uncontrollable acceleration problems of some Toyota vehicles were blamed on Toyota's skewed emphasis on production over quality and clearly fit into the managerial failure category. The subprime mortgage crisis that led to the Great Recession was created by all three managerial causes at several of America's biggest investment banks and mortgage insurers.

Systemic breakdown crises can occur in any complex, tightly coupled organizational environment and usually include unlikely or difficult to anticipate technological failures or technology-human interface errors. The Chernobyl disaster and the flawed Affordable Care Act online rollout fit into this crisis type category.

Finally, a natural disaster crisis occurs when there is damage to life, property, or the environment through weather or other "acts of God." For example, an airliner crashing because of an unpredictable 
microburst is an example of a natural disaster. Another example is when fires forced almost 90,00o people, the entire community of Fort McMurray, Alberta, Canada, to be evacuated in May 2016.

While it has some similarities to what Coombs (2007) called "crisis clusters," this categorization scheme differs in that it does not ask PR practitioners to assess complex patterns of audience perception to match an appropriate image repair strategy. An overarching narrative about the root cause of a crisis is more identifiable, consensual, and stable than estimations of audience organizational knowledge, judgments, and attributions. It is in this way that we believe our approach offers promise as the basis of a more practitioner-friendly and usable crisis response guide.

\section{Image Repair Strategies and Tactics}

This study employed Benoit's (1995a, 1997, 2015) typology, which outlines five general ways people and organizations respond to accusations of wrongdoing: denial, evasion of responsibility, reducing offensiveness of the event, corrective action, and mortification.

Denial includes both simple denial and shifting the blame. Simple denial occurs when the accused rejects the existence of or involvement in the wrongdoing, and shifting the blame occurs when the accused attempts to avoid blame by shifting it to another individual or organization.

Evasion of responsibility includes making one of four tactical arguments: (a) The act was in response to another's wrongful act (provocation), (b) it was not possible to act otherwise given a lack of information or ability (defeasibility), (c) the act was an uncontrollable mistake (accident), or (d) the motivation for the act was positive or virtuous (good intentions).

Reducing offensiveness of an event includes six tactical variants: (a) redirecting negative perceptions by focusing on positive characteristics or good things the accused has done in the past (bolstering), (b) arguing that the act is not as bad as some may think (minimization), (c) making an untoward act look more favorable by comparing it to other less favorable options (differentiation), (d) reframing an issue with a focus on higher and more important issues (transcendence), (e) questioning 
the credibility of whoever is making accusations (attacking the accuser), and (f) alleviating blame by reimbursing victims (compensation).

Finally, corrective action occurs when the accused promises a plan to deal with the consequences of the problem and/or to prevent a similar problem in the future, and mortification occurs when the accused admits responsibility and asks for forgiveness.

Other typologies exist (e.g., Coombs, 1998), though they are less comprehensive. Few have even suggested additions to the Benoit typology, and when suggested (e.g., Brinson \& Benoit, 1999), the additions have not been adopted by later researchers. Therefore the more exhaustive and discriminating nature of Benoit's typology made it the best option for this study.

\section{Participants}

Participants were students attending a mid-sized public university in the Intermountain West of the United States. Instructors of various communication courses were contacted and asked to assist in recruiting individuals from their classes by announcing the opportunity to participate during a class session. Interested students were given information related to accessing an online questionnaire. Cooperating instructors were asked to offer some minimal extra credit as incentive for participation, and all participants were given the opportunity to be entered into a drawing for one of two $\$ 100$ Amazon gift cards by voluntarily identifying themselves by name and cooperating instructor. A total of 323 individuals provided surveys usable for this study. Most students were enrolled in courses that were part of university general education requirements, resulting in a sample broadly representing the campus population.

\section{Online Questionnaire}

Online materials directed participants to indicate consent by marking a check box and advancing to the survey questionnaire. The online questionnaire first directed each participant to read one of four scenariosdetermined by a random selection process-relating to the collapse of a university building balcony that resulted in 95 injured students and 3 deaths. The basic scenario/crisis outcome was the same for all, but each participant received a scenario edited in a way that framed the 
organizational crisis as one of four types based on the ultimate root cause of the crisis: malevolence, managerial failure, systemic failure, and natural disaster. For example, the following was the unique crisis framing for participants who were presented with the malevolence scenario:

Further investigation revealed that the support struts had been purposely weakened. The investigation quickly focused on a disgruntled former employee at the university's maintenance shop who was recently fired. When he was arrested and questioned, the former employee admitted to the crime.

This manipulation allowed for examination of differences in perceived effectiveness of tactics across crisis types.

Then each participant considered 14 possible organizational responses made by the president of the university in follow-up to the crisis. Organizational responses each represented one image restoration tactic reflected in the Benoit (1995a, 2015) typology. For example, the following item was designed to have participants consider a "simple denial" tactic:

Take a moment to reflect again on what you just read about the incident at Millersville State University. Be sure to think through the scenario carefully, stopping to reflect on all the information provided.

Now imagine that, approximately one week after the collapse, you are watching a televised report related to the incident. Part of the report includes video of the President of Millersville State University who has prepared an official statement.

Now imagine the following-Even though the President addresses a number of issues, at the end of the presentation, it seems clear to you that his main point could be summarized as follows: "The university was not in any way responsible for the incident." If the President focused on this in the report, indicate the likely impact that would have on your perception of the university.

Participants were presented with each response individually, one at a time, and rated each response before moving to the next for consideration. They rated each response on a 10-point scale ranging from 1 
(This would have a very negative effect on my perception of the organization) to 10 (This would have a very positive effect on my perception of the organization). The sequence of these 14 organizational responses was randomized for each participant to avoid order bias.

\section{Analysis}

Consistent with the analysis approach taken by Gribas et al. (2016), the data were examined in two ways. First, mean scores for positive and/ or negative impact of each image repair tactics were calculated. These average scores were calculated for the total sample as well as for each of the four crisis types (malevolence, managerial, systemic, natural disaster) to allow for a simple comparison. Second, MANOVA was used, with crisis type serving as the single fixed factor and effect ratings for each of the 14 Benoit image repair tactics serving as multiple dependent variables. Post hoc analysis was performed for all dependent variables showing significance.

\section{Results}

As explained earlier, a random selection process was used to place online survey participants into one of four crisis type groups. Of the 323 participants included in this analysis, 74 responded to a crisis suggesting malevolence, 70 to a crisis suggesting managerial failure, 93 to a crisis suggesting systemic failure, and 86 to a crisis suggesting natural disaster as the root cause.

\section{Rankings of Image Repair Tactics for Crisis Types}

Table 1 shows the means and relative rank ordering of the image repair tactics for each crisis type as well as the means and rank orderings for the overall sample. One thing that stands out from this table is that there is a good deal of similarity across crisis types in terms of the relative rankings of the 14 tactics. Compensation and corrective action were ranked 1 and 2 (or tied for 2), respectively, for all four crisis types, suggesting that these tactics are perceived as having the most positive impact on organizational image regardless of crisis type. In fact, these two tactics along with mortification and good intentions made up the 


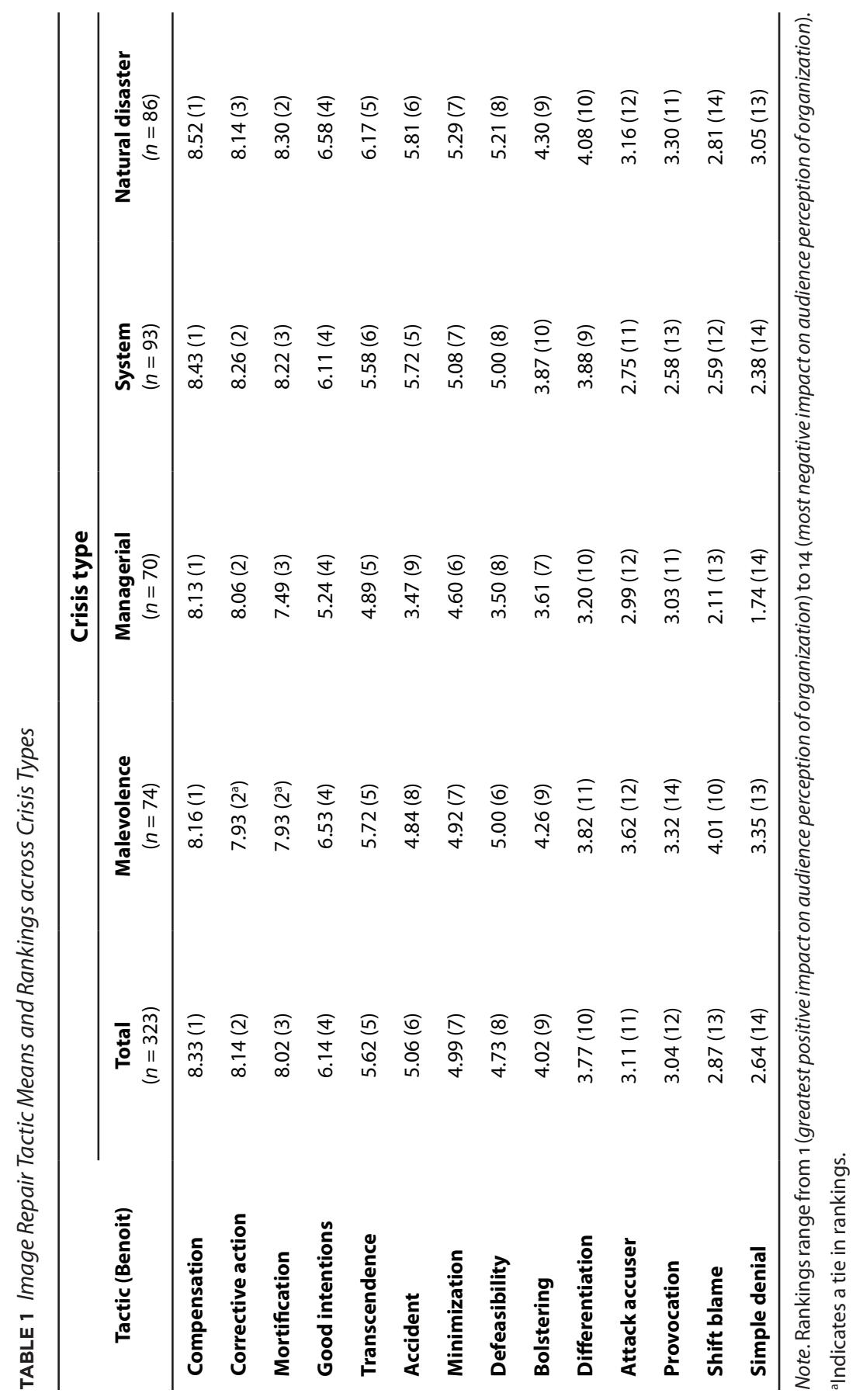


top four spots across all crisis types. These consistencies offer support for previous claims that

corrective action, compensation, and mortification are all likely to help in a crisis and almost certainly will not hurt an organization's image, as long as the image repair messages are perceived by audiences as sincere, and the organization follows through with commitments to correct problems or compensate victims. (Gribas et al., 2016, p. 54)

On the other end of the ranking spectrum, with only minor exceptions, attacking the accuser, provocation, shifting blame, and simple denial were the four tactics perceived as having the most negative impact on organizational image across crisis types. So, overall, the rankings show a good deal of similarity across crisis types for both the highest ranked and lowest ranked tactics. Comparisons of these data to data from earlier research (Gribas et al., 2016) suggest that certain tactics just seem to be overall better and worse regardless of the crisis situation.

\section{MANOVA and Post Hoc Analyses}

The purpose of this study was to uncover ways in which the positive or negative impacts of particular image repair tactics seem to be dependent on crisis type. The foregoing consideration of means and relative rankings of tactics across crises suggests that crisis type makes rather little difference. However, results from a more robust analysis, applying MANOVA and follow-up post hoc procedures, offer more finely tuned insights.

The results of the MANOVA were statistically significant, $F(42$, $924)=3.436, p<.000$, Pillais's trace $=.405$, partial $\eta^{2}=.135$, supporting the idea that the degree to which image repair tactics influence audience perceptions of an organization during a crisis is impacted by crisis type. Because of this, follow-up ANOVAs were conducted to determine which of the 14 tactics seem to be dependent on crisis type. A Bonferroni correction suggested applying an alpha of .0036 or lower to indicate significance for the follow-up ANOVAs.

From the follow-up ANOVAs, 5 of the 14 tactics showed significance based on the corrected alpha: simple denial, $F(3,319)=9.961$, 


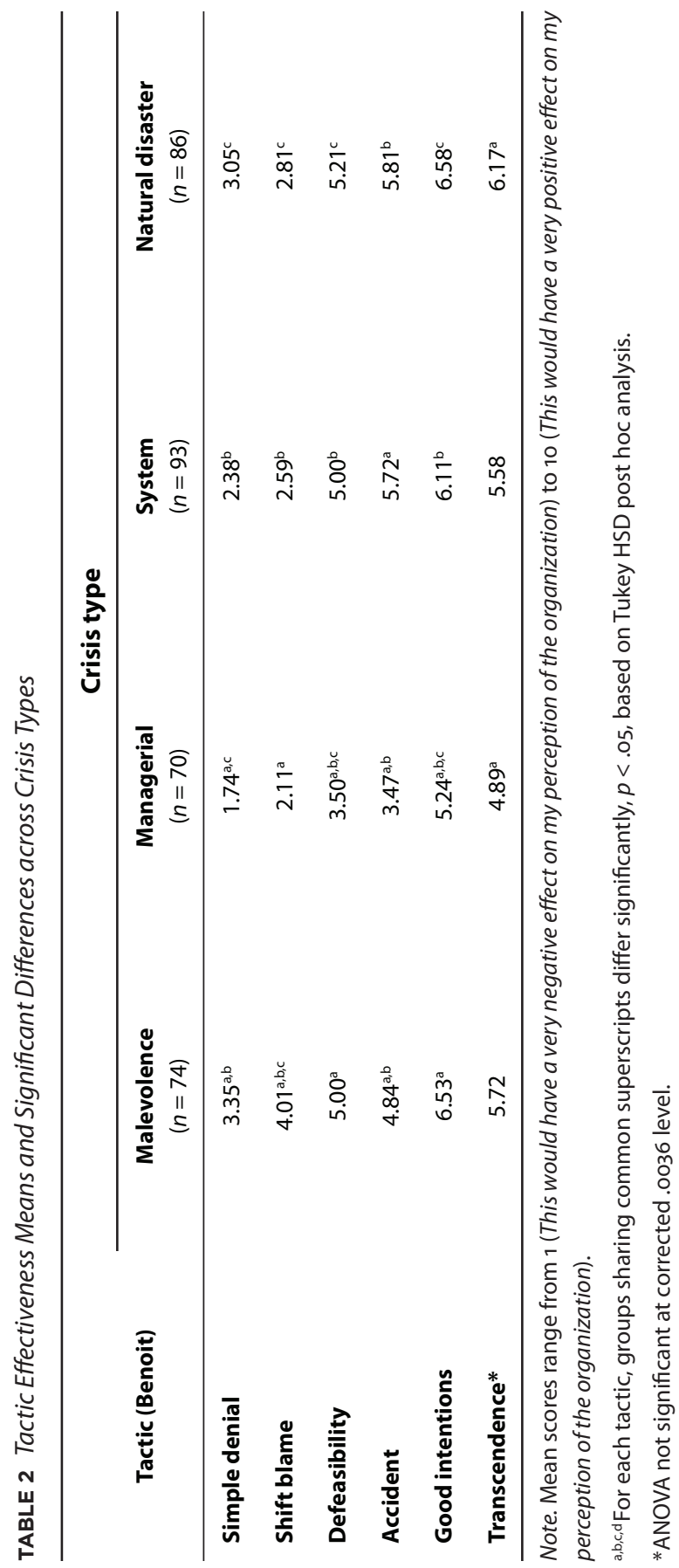


TABLE 3 Significant Tactic Effectiveness Differences for Crisis Type Pairings

\begin{tabular}{|c|c|c|c|}
\hline \multirow[b]{2}{*}{ Crisis type } & \multicolumn{3}{|c|}{ Crisis type } \\
\hline & Managerial & Systemic & Natural disaster \\
\hline Malevolence & $\begin{array}{l}\text { simple denial } \\
\text { shift blame } \\
\text { defeasibility } \\
\text { accident } \\
\text { good intentions }\end{array}$ & $\begin{array}{l}\text { simple denial } \\
\text { shift blame } \\
\text { accident }\end{array}$ & $\begin{array}{l}\text { shift blame } \\
\text { accident }\end{array}$ \\
\hline Managerial & & $\begin{array}{l}\text { defeasibility } \\
\text { accident } \\
\text { good intentions }\end{array}$ & $\begin{array}{l}\text { simple denial } \\
\text { defeasibility } \\
\text { accident } \\
\text { good intentions } \\
\text { transcendence }\end{array}$ \\
\hline
\end{tabular}

Systemic

$p<$.ooo; shifting blame, $F(3,319)=11.693, p<.000 ;$ defeasibility, $F(3,319)=10.989, p<.000$; accident, $F(3,319)=22.457, p<.000$; and good intentions, $F(3,319)=6.692, p<.000$. Results for transcendence, $F(3,319)=3.885, p<.009$, approached significance at the corrected level and would have been highly significant for an uncorrected ANOVA. Because of this, and because of the unique nature of transcendence noted in related research by Gribas et al. (2016), it was included in follow-up considerations.

Tables 2 and Table 3 show relevant information for the six tactics considered here. Table 2 includes mean scores for interpretation and also includes superscript designations that identify sets of crisis types for which specific tactic ratings significantly differ. Table 3 simplifies this same information by eliminating mean scores and, instead, listing all tactics that showed significant differences for particular crisis type pairings.

None of the tactics in Table 2 was among the very highest ranking overall tactics (see Table 1). Of the tactics that showed significant 
differences across crisis type, good intentions, transcendence, and accident were ranked 4, 5, and 6, respectively, overall; defeasibility fell in the middle of the tactic ranking order; and simple denial and shifting blame were the bottom two ranked tactics overall. So the consistency in relative rankings for the highest ranked tactics noted earlier appears to be validated by the lack of significant differences found in the post hoc analysis. On the other hand, despite general consistency in relative rankings for lowest ranked tactics (Table 1), simple denial and shifting blame in particular still reflect statistically significant differences across crisis type.

Table 3 shows that there were significant differences for five tactics across the managerial-malevolence crisis type pairing. The same was true for the managerial-natural disaster pairing. In fact, four of the five tactics showing significant differences in these two pairings were the same: simple denial, defeasibility, accident, and good intentions. In all cases, these tactics were perceived as having a more negative impact on organizational image in the managerial crisis case than in either the malevolence case or the natural disaster case. For the managerialmalevolence pairing, shifting blame showed a similar pattern, and for the managerial-natural disaster pairing, transcendence showed the same pattern.

So these two pairings, managerial-malevolence and managerialnatural disaster, reflected the greatest number of significant differences. The managerial-systemic pairing also reflected significant differences; managerial significantly differed from systemic for the simple denial, shifting blame, and accident tactics. All three of these tactics were viewed as more problematic for the managerial crisis situation than for the systemic failure crisis situation.

As noted, the malevolence crisis situation differed significantly from the managerial crisis situation. Malevolence also showed significant differences from systemic and from natural disaster. Specifically, simple denial, shifting blame, and accident differed significantly in the malevolence-systemic pairing, while shifting blame and accident differed significantly in the malevolence-natural disaster pairing. So just as managerial differed from all other crisis types in some way, malevolence similarly differed from all others. In every case of significant 
difference, tactic effectiveness ratings were lower for managerial than for all other crisis types, but that was not true for malevolence pairings. The accident tactic was viewed less positively for malevolence than for systemic or natural disaster, but in all other cases, tactics showing significant differences were viewed more favorably in a malevolence crisis situation than for other crisis types.

Finally, the only crisis type pairing for which no significant differences emerged was systemic-natural disaster. This does make some intuitive sense, especially given that image repair is always a response addressing issues of crisis event responsibility and causality. Systems may be designed by human agents, but the interdependence of system parts and the complexity of many systems are such that identifying any individual source for blame or for attributing causality would be difficult at best. Similarly, most accept that a natural disaster is an unpredictable event that defies any kind of causal attribution.

\section{Discussion and Conclusions}

Effective crisis planning requires reliable insight into image repair tactic selection. The root cause crisis type scheme applied in this study seemed to work well to identify unique variations regarding tactic appropriateness. Overall, our results demonstrate that compensation, corrective action, and mortification are broadly effective strategies to use, while the remaining strategies are either not recommended or should be applied only after careful consideration of root cause as well as audience and situational particulars.

We have noted that effective crisis planning must allow practitioners to deal with a crisis quickly, avoid speculation, and "provide insights that can be applied effectively and ethically under extraordinary pressures of limited time and severe scrutiny of the organization's legitimacy" (Heath, 2010, p. 3). Given this challenge, guidelines like the ones just suggested, although helpful, may be too general to guide truly strategic crisis planning. Therefore we offer the following crisis planning tactic selection guidelines based on the results of this study.

Recall that the scale used to rate image repair tactic appropriateness ranged from a low of 1 (This would have a very negative effect on 
my perception of the organization) to a high of 10 (This would have a very positive effect on my perception of the organization). It makes some intuitive sense to split that range exactly in half at a score of 5.5 and to consider tactics rated in the upper half as ones we would recommend. This approach would be reasonable because we would be recommending tactics rated as having at least some overall positive effect on improving people's perceptions of the organization. However, given the somewhat negatively skewed distribution of scores for these tactics, such an approach would lead us to "not recommend" the vast majority of strategies under any circumstances. This would offer a very limited and limiting set of options to practitioners designing crisis response plans. Instead, for the purposes of suggesting crisis plan recommendations, we determined that tactics scoring an average of above 5.0 should be categorized as "recommend" and anything at or below 5.0 categorized as "do not recommend." Though a tactic with an average score between 5.0 and 5.5 is still technically on the "would have a negative effect" side of the continuum, we can safely deduce that, to achieve that average, a good percentage of respondents did rate it positively. For example, the overall average across crisis types for the accident strategy was 5.0; however, almost $40 \%$ of all respondents rated that strategy from 6 to 10, indicating that it would have some degree of positive effect on their perceptions.

In the world of crisis management, it is often the case that the goal is to minimize damage rather than to prevent it and to do as much good as possible with as many as possible. Finding strategies that make sense for a particular crisis situation that are likely to have a positive impact on most or all is likely unrealistic. Therefore we suggest the following in terms of tactics recommended and not recommended for consideration as part of a crisis response plan targeted to particular crisis types:

For Any Crisis Type

- Recommend: compensation, corrective action, mortification, good intentions

- Do not recommend: simple denial, shift blame, attack accuser, differentiation, bolstering, provocation 
Additions for Malevolence Crisis Type

- Recommend: transcendence

- Do not recommend: accident, minimization, defeasibility

Additions for Managerial Failure Crisis Type

- Recommend: N/A

- Do not recommend: accident, minimization, defeasibility, transcendence

Additions for Systemic Failure Crisis Type

- Recommend: transcendence, accident, minimization

- Do not recommend: defeasibility

Additions for Natural Disaster Crisis Type

- Recommend: transcendence, accident, minimization, defeasibility

- Do not recommend: N/A

These guidelines reinforce our earlier discussion; a handful of tactics, no matter the crisis, are most likely to improve the organization's image among audience members. Three of these-compensation, corrective action, and mortification-are consistent with what Coombs called "accommodative" strategies or tactics that focus on victims' concerns. Conversely, six tactics appear to have a more negative effect on audience perceptions of the organization across all crisis types. Four of these-simple denial, shifting the blame, attacking the accuser, and provocation-are similar to Coombs's description of "defensive" strategies that work more to protect the organization. Therefore the results reinforce that, if it is at all possible, organizations experiencing a crisis should adopt accommodative tactics and avoid defensive tactics.

However, this general principle cannot be fully embraced, because accident and defeasibility are clearly defensive rather than accommodative, and these show on the "recommend" list for some crisis types. Additionally, avoiding the defensive tactics is not always possible or reasonable. During the 1993 Pepsi scare, when foreign objects (syringes, 
bullets, etc.) were found in the soft drink's cans and plastic bottles, the Pepsi crisis team engaged in simple denial, claiming that the objects could not have been introduced at the bottling plant. Pepsi circulated press releases with vivid graphics showing bottles hanging upside down until a split second before they were filled, demonstrating the difficulty of inserting objects at the plant. Pepsi's claims were supported by the Food and Drug Administration's commissioner, David Kessler, who agreed Pepsi was the victim of copycat hoaxes. Additionally, surveillance cameras in a Colorado supermarket showed a woman opening a Pepsi and inserting a syringe into it. Though simple denial is not an accommodative strategy, most experts believe Pepsi was successful in restoring its image (Holmes, 1993). However, the Pepsi example also demonstrated that, for denial to be effective, organizations must summon an enormous amount of evidence for this defensive tactic to work effectively.

\section{Managerial Crisis}

It is clear by looking at the "recommend" tactics that the managerial crisis presents the most difficult situation for the PR practitioner, because only the four tactics recommended for all crisis types seem likely to improve the audience's perception of the organization. Managerial crises are created through skewed management values, deception, misconduct, or some combination of the three. Because responsibility for the crisis rests so heavily on the organization and its leadership, it makes sense that the only real options available all admit that a crisis occurred and then attempt to compensate, correct, or apologize for that event. For example, in 2016, Wells Fargo Bank experienced a serious managerial crisis when thousands of employees created 1.5 million fake accounts and 565,00o credit card accounts for existing customers, none of which were authorized by those customers, to earn bonuses and meet aggressive sales targets (Comcowich, 2016). Although the firm apologized and eventually engaged in corrective action by discontinuing the incentive program, they shifted the blame to (and fired) 5,300 lower level employees. Unfortunately, this failed to address the real problem: skewed management values that focused on the short-term profits of cross-selling. 
Our tactical guidelines imply that shifting the blame likely would have had a negative effect on people's perceptions of the organization, and that is exactly what happened with Wells Fargo. The organization's attempt to shift the blame overshadowed its other image repair tactics and brought them stinging rebukes from the media and Senator Elizabeth Warren on the Senate Committee on Banking, Housing, and Urban Affairs, among others (Peck \& Carter, 2016). Therefore, in a managerial crisis, organizations must focus on compensation, corrective action, mortification, and good intentions and do everything possible to steer clear of other tactics.

\section{Malevolence Crisis}

Five tactics have potential to improve the audience's perception of the organization in a malevolence crisis situation: compensation, corrective action, mortification, good intentions, and transcendence. Significance tests showed that, although shifting the blame does not necessarily help the organization's image, it is at least a significantly more acceptable tactic for malevolence than for any of the other three crisis types. This makes sense given that the malevolent actor is an easy target for blame shifting, and this tactic, combined with several of the recommended tactics, might be effective at improving the organization's image.

\section{Systemic Crisis}

There are seven recommended tactical options available for improving the organization's image in a systemic failure crisis: compensation, corrective action, mortification, good intentions, accident, transcendence, and minimization. In systemic failure crises, even a number of tactics considered defensive seem to be seen as potentially effective. Significance testing shows that good intentions is viewed more positively in the systemic crisis than in the managerial crisis, and accident is viewed more positively in the systemic crisis than in either the managerial or malevolence crisis. Although shifting the blame is not recommended for any crisis type, it is seen as significantly more positive (or less negative) for the systemic crisis than for the managerial crisis. 


\section{Natural Disaster}

The natural disaster crisis offers the organization the largest number of recommended image repair tactical options, including compensation, corrective action, mortification, good intentions, transcendence, accident, minimization, and defeasibility. By its definition, a natural disaster is difficult to predict and impossible to control. Given the unpredictable nature of natural disasters, it makes sense that good intentions and appeals to accident would work in these circumstances, despite the fact that they are on the defensive end of the continuum. The natural disaster suggests little to no organizational responsibility, and therefore there seems to be a larger number of legitimate tactical possibilities.

\section{Limitations}

These results and our tactical guide clearly identify strategies that are and are not recommended. However, recommendations based on the public's positive or negative ratings of tactics may not be consistent with realities faced by PR practitioners. For example, we outlined earlier some instances where denial might need to be used, even though generally it is not seen positively as a strategy. On the other hand, mortification (taking responsibility and making an apology) was rated positively for all crisis types. However, PR practitioners must be aware that an apology can come with legal ramifications. According to Meyers (2016), there are currently 38 "I'm sorry" laws taking multiple forms spanning 37 states and the District of Columbia. Twenty of the jurisdictions exempt fault-based apologies from evidence, while 18 jurisdictions include fault-based apologies in evidence. When considering an apology, PR practitioners must be aware of state laws, and when legal and financial liability risks are high, they must consider the use of language that emphasizes sympathy and empathy while minimizing fault. This would be in line with findings by Coombs and Holladay (2008) that "respondents had similar reactions to sympathy, compensation, and apology response strategies" (p. 255). PR practitioners must also evaluate and manage any nonverbal apologies (Meyers, 2016).

For a practitioner guide to be truly useful, it should be dependable as a resource across crisis types, contexts, and audiences. While 
we hope our proposed guidelines offer such versatility of application, we know that the design of this study has limitations that make broad application something to be proved in practice and over time. To consider the relative impact of 14 different crisis tactics and avoid impossible complication of research design and analysis, it was necessary to work with a single crisis scenario with some modifications to suggest various crisis types. We believe this approach was justified to avoid seriously confounding the results. If, for instance, the managerial crisis had dealt with some financial impropriety while the malevolence crisis dealt with some dangerous equipment failure and the systemic and natural disaster crises were similarly distinct in nature, this would have introduced a confounding variable into the study. So, for purposes of control, the approach taken here was to keep the crisis scenario consistent across conditions. At the same time, it does mean that the results and implications could be limited to similar crisis scenarios. Our scenario involved an organization that was relatively large, loosely coupled (Weick, 1976), and institutional, and the crisis outcome was rather serious in that it resulted in bodily injury and multiple deaths. It is reasonable to question whether the same results would be seen if considering these same crisis types for a smaller, for-profit, corporate firm in a rapidly changing competitive market or with a crisis that had different, much less serious consequences.

We also acknowledge the limitations of looking at individual tactics out of context. Respondents were directed to consider a crisis response characterized by 14 image repair tactics, but, by design, they were asked to consider the tactics individually and one at a time. However, it would be a rare occurrence indeed for even a very brief crisis response to rely on a single tactic. In response to crises, multiple image repair tactics are typically used together in ways, it is hoped, that are seen as consistent and complementary.

\section{Future Research}

We believe that the preceding guidelines have face validity. In light of the limitations discussed, though, we suggest that they should be applied with due caution, at least until future research offers greater validation. Such research would do well to intentionally consider a different crisis 
scenario than used here or, even better, to limit consideration to one or a few image repair tactics applied to a variety of crisis scenarios. Additionally, future work might do well to explore the interplay of tactic combinations. Given the promising results by Gribas et al. (2016) and from the current study, we believe that such research building on, extending, and, we hope, validating this work is warranted.

Although we advocate this continued exploration, we also note that the findings here, as well as in past related research, were not particularly striking in terms of application. For example, in this study, most of the tactics showing significant differences across crisis type were middleof-the-road tactics; that is, with the exception of simple denial and shifting the blame, they were tactics viewed as not highly effective nor as highly ineffective. For the most part, crisis type seems most relevant when considering image repair tactics that, at best, may have a slightly positive to slightly negative impact on audience perception. Stronger findings related to tactics with greater positive or negative impact would have offered something more worthy of a PR practitioner's attention.

What is striking is how similar these findings are to those from other studies (Brown \& White, 2011; Claeys et al., 2010; Coombs \& Holladay, 1996; Gribas et al., 2016). The search for the ideal tactics to suit particular crises, audience types, and other situational variables has yet to reveal exceptional and compelling prescriptive advice for practitioners. Given this, it seems possible that the way people perceive organizational image repair attempts may rest in something less situational and more in cultural notions of effective "apologia." As applied in rhetorical criticism, apologia is understood as a formal defense or justification of actions. The results of these organizational image repair studies, all of which have utilized U.S. participants, suggest that there might be an underlying cultural apologia script that demands organizations in crisis embrace certain culturally appropriate accommodative responses and avoid certain culturally inappropriate defensive responses. So it may be that there are culturally derived social scripts dictating proper organizational image repair efforts, no matter the type of crisis or audience.

Initial support for this possibility has been found in a work in progress by DiSanza, Legge, Hartman, Carr, and Gribas (2017) that compared 
U.S. and Middle Eastern respondents in regard to their perceptions of the effectiveness of various image repair tactics. Preliminary analyses suggested that U.S. participants responded very favorably to accommodative tactics and very negatively to defensive tactics; however, Middle Eastern audiences did not seem to have the same degree of negative response to defensive tactics. In fact, for this Middle Eastern sample, differences between the most defensive tactics and the most accommodative tactics were negligible. Though this is still quite speculative, we suggest that cross-cultural studies of the effectiveness of image repair tactics is one fruitful new direction for future organizational crisis response research.

James DiSanza, $\mathrm{PhD}$, is a professor in the Department of Communication, Media, and Persuasion at Idaho State University. He teaches courses in leadership, business and professional communication, and conflict management. His research interests are in persuasive attack and image repair rhetoric.

John Gribas, $\mathrm{PhD}$, is a professor in the Department of Communication, Media, and Persuasion and associate dean in the College of Arts and Letters at Idaho State University. His work focuses on how language choices impact human thought and action.

Karen L. Hartman, $\mathrm{PhD}$, is an associate professor in the Department of Communication, Media, and Persuasion at Idaho State University. Her research interests revolve largely around the role of sport in the United States and how language and public relations efforts frame athletes, organizations, and laws.

Nancy J. Legge, $\mathrm{PhD}$, is a professor in the Department of Communication, Media, and Persuasion at Idaho State University. She studies image repair analysis and rhetorical analysis of popular culture artifacts. 


\section{ORCID}

John Gribas (1) https://orcid.org/oooo-0oo3-3915-8131

James DiSanza (D) https://orcid.org/oooo-00o2-3356-0886

Nancy J. Legge (D) https://orcid.org/oooo-0002-6250-5325

Karen L. Hartman (D) https://orcid.org/oooo-0oo3-1806-4988

\section{References}

An, S., \& Cheng, I. (2010). Crisis communication research in public relations journals: Tracking research trends over thirty years. In W. T. Coombs \& S. J. Holladay (Eds.), The handbook of crisis communication (pp. 65-90). Malden, MA: Wiley-Blackwell.

Avery, E. J., Lariscy, R. W., Kim, S., \& Hocke, T. (2010). A quantitative review of crisis communication research in public relations from 1991 to 2009. Public Relations Review, 36, 190-192. https://doi.org/10.1016/j.pubrev.2010.01.001

Benoit, W. L. (1995a). Accounts, excuses, and apologies: A theory of image restoration strategies. Albany, NY: SUNY Press.

Benoit, W. L. (1995b). Sears' repair of its auto repair image: Image restoration discourse in the corporate sector. Communication Studies, 46, 89-109. https://doi.org/10.1080/10510979509368441

Benoit, W. L. (1997). Image repair discourse and crisis communication. Public Relations Review, 23, 177-186. https://doi.org/10.1016/So363-8111(97)90023-0

Benoit, W. L. (2006). President Bush's image repair effort on Meet the Press: The complexities of defeasibility. Journal of Applied Communication Research, 34, 285-306. https://doi.org/10.1080/oo909880600771635

Benoit, W. L. (2015). Accounts, excuses, and apologies (2nd ed.). Albany, NY: SUNY Press.

Benoit, W. L., \& Brinson, S. L. (1994). AT\&T: Apologies are not enough. Communication Quarterly, 42, 75-88. https://doi.org/10.1080/01463379409369915

Benoit, W. L., \& Czerwinski, A. (1997). A critical analysis of USAir's image repair discourse. Business Communication Quarterly, 6o, 38-57. https:// doi.org/10.1177/108056999706000304

Blaney, J. R. (2016). Putting image repair to the test. Lanham, MD: Lexington Books. 
Brinson, S. L., \& Benoit, W. L. (1999). The tarnished star: Restoring Texaco's damaged public image. Management Communication Quarterly, 4, 483-510. https://doi.org/10.1177/0893318999124001

Brown, K. A., \& White, C. L. (2011). Organization-public relationships and crisis response strategies: Impact on attribution of responsibility. Journal of Public Relations Research, 23, 75-92. https://doi.org/10.1080/1062726X.2010 .504792

Campbell, R. (1999). Crisis control: Preventing and managing corporate crises. Mayborough, Australia: Prentice Hall Australia.

Claeys, A.-S., Cauberghe, V., \& Vyncke, P. (2010). Restoring reputations in times of crisis: An experimental study of the situational crisis communication theory and the moderating effects of locus of control. Public Relations Review, 36, 256-262. https://doi.org/10.1.1.456.9889

Comcowich, W. (2016, September 20). Experts call Wells Fargo's crisis response lacking [Web log post]. Retrieved from http://www.cyberalert.com/blog /index.php/experts-call-wells-fargos-pr-crisis-response-lacking/

Coombs, W. T. (1998). An analytic framework for crisis situations: Better responses from a better understanding of the situation. Journal of Public Relations Research, 10, 177-192. https://doi.org/10.1207/s1532754xjprr1003_02

Coombs, W. T. (1999). Ongoing crisis communication: Planning, managing, and responding. Thousand Oaks, CA: Sage.

Coombs, W. T. (2006). The protective powers of crisis response strategies: Managing reputational assets during a crisis. Journal of Promotion Management, 12, 241-26o. https://doi.org/10.1300/Jo57v12no3_13

Coombs, W. T. (2007). Protecting organization reputations during a crisis: The development and application of situational crisis communication theory. Corporate Reputation Review, 10, 163-176. https://doi.org/10.1057 /palgrave.crr.1550049

Coombs, W. T. (2014). State of crisis communication: Evidence and the bleeding edge. Research Journal of the Institute for Public Relations, 1(1). Retrieved from http://www.instituteforpr.org/state-crisis-communication -evidence-bleeding-edge/

Coombs, W. T., \& Holladay, S. J. (1996). Communication and attributions in a crisis: An experimental study in crisis communication. Journal of Public Relations Research, 8, 279-295. https://doi.org/10.1207/s1532754xjprro804_04 Coombs, W. T., \& Holladay, S. (2008). Comparing apology to equivalent crisis 
response strategies: Clarifying apology's role and value in crisis communication. Public Relations Review, 34, 252-257. https://doi.org/10.1016/j .pubrev.2008.04.001

Coombs, W. T., \& Schmidt, L. (2000). An empirical analysis of image restoration: Texaco's racism crisis. Journal of Public Relations Research, 12, 163-178. https://doi.org/10.1207/S1532754XJPRR1202_2

Cos, G., Worrell, T. R., \& Blosenhauser, J. D. (2016). An empirical test of image restoration strategies. In J. Blaney (Ed.), Putting image repair to the test: Quantitative applications of image restoration theory (pp. 85-97). Lanham, MD: Lexington Books.

Dawar, N., \& Pillutla, M. M. (200o). Impact of product-harm crises on brand equity: The moderating role of consumer expectations. Journal of Marketing Research, 37, 215-226. https://doi.org/10.1509/jmkr.37.2.215.18729

DiSanza, J. R., Legge, N. J., Allen, H. R., \& Wilde, J. T. (2012). The puck stops here: The NHL's image repair strategies during the 2004-2005 lockout. In J. R. Blaney, L. R. Lippert, \& J. S. Smith (Eds.), Repairing the athlete's image: Studies in sports image restoration (pp. 319-357). Lanham, MD: Lexington Books.

DiSanza, J., Legge, N., Hartman, K., Carr, J., \& Gribas, J. (2017). Exploring the success of image repair tactics across different organizational crises among Middle-Eastern and American populations. Manuscript in preparation.

Gribas, J., DiSanza, J., Legge, N., Hartman, K., \& Santee, C. (2016). Exploring the alignment of image repair tactics to audience type (pp. 41-61). In J. R. Blaney (Ed.), Putting image repair to the test: Quantitative applications of image restoration theory (pp. 41-61). Lanham, MD: Lexington Books. Heath, R. L. (2010). Introduction crisis communication: Defining the beast and de-marginalizing key publics. In W. T. Coombs \& S. J. Holladay (Eds.), The handbook of crisis communication (pp. 1-13). Malden, MA: Wiley-Blackwell.

Holmes, P. (1993, July 6). How the Pepsi syringe hoax fizzled (1993) [Blog post]. Retrieved from http://www.holmesreport.com/latest/article/how -the-pepsi-syringe-hoax-fizzled-(1993)

King, G., III. (2006). Image restoration: An examination of the response strategies used by Brown and Williamson after allegations of wrongdoing. Public Relations Review, 32, 131-136. https://doi.org/10.1016/j.pubrev.2006.02.006 Lerbinger, O. (1997). The crisis manager: Facing risk and responsibility. Mahwah, NJ: Erlbaum. 
Meyers, C. (2016). Apology, sympathy, and empathy: The legal ramifications of admitting fault in US public relations practice. Public Relations Review, 42(1), 176-183. https://doi.org/10.1016/j.pubrev.2015.10.004

Peck, E., \& Carter, Z. (2016, September 20). Elizabeth Warren hammers Wells Fargo CEO: "You should be criminally investigated." Huffington Post. Retrieved from http://www.huffingtonpost.com/entry/elizabeth-warren -john-stumpf-wells-fargo_us_57e1591ee4bo4a1497b6caae

Pfeffer, J., \& Sutton, R. I. (2006). Evidence-based management. Harvard Business Review, 84(1), 62-74.

Preparing for crisis. (2014). Retrieved from http://www.steelhenge.co.uk/im ages/CMC2014/Survey/Crisis\%2oManagement\%2oSurvey\%202014\%20 Report_secure.pdf

Spence, P. R., Lachlan, K. A., \& Omilion-Hodges, L. M. (2016). Examining the impact of message strategy on organizational image. In J. Blaney (Ed.), Putting image repair to the test: Quantitative applications of image restoration theory (pp. 29-39). Lanham, MD: Lexington Books.

Twork, J., \& Blaney, J. (2013). Reputation differences between mortificationonly and mortification/corrective action strategies following a transgression by a professional athlete. In J. R. Blaney, L. R. Lippert, \& J. S. Smith (Eds.), Repairing the athlete's image: Studies in sports image restoration (pp. 395-399). Lanham, MD: Lexington Books.

Weick, K. E. (1976). Educational organizations as loosely coupled systems. Administrative Science Quarterly, 21, 1-19. https://doi.org/10.2307/2391875 